\title{
Synthesis and Characterization of Zr-Doped Vanadium Oxide Nanotubes
}

\author{
Azita Saliman ${ }^{1, ~ *, ~ H a m i d ~ R e z a ~ A g h a b o z o r g ~}{ }^{1,2}$, Sepideh Ketabi ${ }^{3}$ \\ ${ }^{1}$ Department of Chemistry, North Tehran Branch, Islamic Azad University, Tehran, Iran \\ ${ }^{2}$ Research Institute of Petroleum Industry (RIPI), Tehran, Iran \\ ${ }^{3}$ Department of Chemistry, East Tehran Branch, Islamic Azad University, Tehran, Iran
}

Email address:

azita_salimian_chem@yahoo.com (A. Salimian)

${ }^{*}$ Corresponding author

\section{To cite this article:}

Azita Saliman, Hamid Reza Aghabozorg, Sepideh Ketabi. Synthesis and Characterization of Zr-Doped Vanadium Oxide Nanotubes. American Journal of Chemical Engineering. Vol. 6, No. 4, 2018, pp. 49-53. doi: 10.11648/j.ajche.20180604.12

Received: May 15, 2018; Accepted: June 8, 2018; Published: July 27, 2018

\begin{abstract}
In this research study for the firsttime zirconium doped vanadium oxide nanotubes (VONTs) were synthesized. Zr-doped VONTs were performed by using hydrothermal method. Zr-VONTs prepared 0.02 wt $\%$. The structure and morphology of the nanotubes were investigated by $\mathrm{x}$ - ray diffraction (XRD), scanning electron microscopy (SEM) and transmission electron microscopy (TEM). In contrast to the undoped VONTs, the interlayer distance between oxide layers in the $\left(\mathrm{V}_{0.98} \mathrm{Zr}_{0.02}\right)_{\mathrm{x}}$ ONTs increases owing to replacement of some $\mathrm{V}$ in nanotubes by $\mathrm{Zr}$ with a large ionic radius. The results showed that zirconium $0.02 \mathrm{wt} \%$ doped VONTs complately and the doping Zr into VONTs leads to increasing interlayer distances.
\end{abstract}

Keywords: Vanadium Oxide Nanotubes (VONTs), Zirconium (Zr), Hydrothermal, Doped

\section{Introduction}

Synthesis of different kinds of nanotubes as Inorganic nanotubes were considering after the discovery of carbon nanotubes [1]. One inorganic nanotubes $\left(\mathrm{WS}_{2}\right)$ synthesized in 1992 [2], $\left(\mathrm{MoS}_{2}\right)$ in 1993 [3], (BN), $\left(\mathrm{Sio}_{2}\right) 1995$ [4, 5], $\left(\mathrm{Tio}_{2}\right)$, $\left(\mathrm{VO}_{\mathrm{x}}\right)$ in 1998 [6, 7], $\left(\mathrm{Nicl}_{2}\right),\left(\mathrm{NbSe}_{2}\right)$ in 2000 [8, 9], etc. Methods for synthesizing inorganic nanotubes, together simulations of their structure and predictions of their properties, have been reviewed by Ivanovski [10]. The inner and outer diameters of the nanotubes varied from 20 to $40 \mathrm{~nm}$ and 80 to $100 \mathrm{~nm}$. The nanotubes measured several micrometers in length [11]. Spahr et al [12] first synthesized redox active vanadium oxide, using vanadium alkoxide as a precursor while primary amines as structure directing agants. Later, nanotubular vanadium oxides were successfully synthesized by $\mathrm{V}_{2} \mathrm{O}_{5}$ or $\mathrm{VOCl}_{3}$ precursors [13] and aromatic amine structure directing agant [14]. Inorganic nanotubes have potential application in catalytic processes and electrochemical properties $[15,16]$. Vanadium oxide nanotubes is similar to that of carbon nanotubes discovared by Iijima in 1991 [1].
Vanadium oxide nanotubes are made of multilayer scrolls with thick walls built up from several vanadium oxide layers [17]. Vanadium oxide nanotubes are useful materials due to their widely used for dehydrogenation or partial oxidations of alkanes to olefins [18-23]. The prepared VONTs sensors excellent sensing sensitivity and superior recovery property in detecting ethanol vapor [24, 25-27], nitric oxide, oxygen, nitrogen oxide [28], trimethylamine (TEA) and dimethylmethylphosphonate (DMMP) [29], and so on. The VONTs is of p-type behavior at $80^{\circ} \mathrm{C}$.

Among the various nanostructure, vanadium oxide is an important material for sensing materials. In particular VONTs have recently attracted attention because they offer a large active surface area and numerous channels for ionic transport owing to their multiwalled tubular structures [2-7]. The tubular morphology of the vanadium oxide is particularly attractive since it provide access to the three different contact regions: inner and outer surface as well as the tube ends [30], and these make the VONTs likely to be good sensor materials [31]. The ends of these nanotubes are open, so different cations can be introduced into the inner cavity of the nanotubes [8]. This 
nanotubes offer four different contact regions, namely, the tube ends, the inner and outer wall surfaces as well as the interwalls spaces. Vanadium oxide nanotubes can provide electrolyte-filled channels [32]. If are entering metallic ions into NT structure (doping process), certainly it has its effect on the magnetic and electric its behavior [32] and interlayer distances. Mai et al (2003) [34] reported doping molybdenum, tungsten, and copper. Li et al (2007) [33] and jiao et al (2006) [35] and rouhani et al (2011) respectively [2, 9, 12-16]. Different amount for doping can be Creating different results. Therefore type and amount of metal doping is important $[1,36]$. Vanadium oxide nanotubes $\left(\mathrm{VO}_{\mathrm{x}}-\mathrm{NTS}\right)$ are useful material and have applicability in chemical process. Different types if vanadium oxide consists of vanadium pentaoxide $\left(\mathrm{V}_{2} \mathrm{O}_{5}\right)$, vanadium dioxide $\left(\mathrm{VO}_{2}\right)$ vanadium oxy trichloride $\left(\mathrm{VOcl}_{3}\right)$ and vanadic acid $\left(\mathrm{HVO}_{3}\right)$ as vanadium Source Are used for successful synthesis of vanadium oxide nanotubes [37].

In this research zirconium ( $\mathrm{Zr}$ ) doped VONTs were synthesized and characterized for the first time. $\mathrm{Zr}$ doped vanadium oxides have found a wide range of application because of their selective oxidation [32]. Zirconium (zr) is widely in biomedical applications as orthopedic, and dental implant materials but pure $\mathrm{zr}$ metal cannot bond directly with bone [38]. Zr doped vanadium oxide nanotubes (VONTS) were prepared by hydrothermal method that organic molecules as structure directing templates in hydrothermal method [36]. The nanotubes were characterized by $\mathrm{X}$ - ray diffraction (XRD), scanning electron microscopy (SEM) and transmission electron microscopy (TEM).

\section{Experimental}

Vanadium oxide nanotubes were hydrothermal synthesized from a mixture of $\mathrm{V}_{2} \mathrm{O}_{5}, \mathrm{C}_{12} \mathrm{H}_{25} \mathrm{NH}_{2}$ and distilled water. The $\mathrm{Zr}$ doped VONTs were prepared with $\mathrm{V}_{2} \mathrm{O}_{5}\left(>99 \%\right.$, merck) $\mathrm{ZrO}_{2}$ $(>99 \%$, merck) and dodecylamine $(>98 \%$, merck) as a template were mixed in the molar ratio $\left(\mathrm{V}_{1-\mathrm{x}} \mathrm{Zr}_{\mathrm{x}}\right)_{\mathrm{y}}$ ONTs $(\mathrm{x}=0.02)$ In distilled water, and the mixture were stirred for $48 \mathrm{~h}$ in air. The resulting mixture (gel) was shall [1]. The autoclave was kept at $180^{\circ} \mathrm{C}$ for 4 days and then allowed to cool naturally. The abtained product was washed with hexan and absolute ethanol and then dried. The powder suggested that some $\mathrm{V}^{+5}$ ions were reduced to $\mathrm{V}^{+4}$ by decomposition of the organic compound [39]. X-ray powder diffraction (XRD) patterns of the prepared samples were obtained using pw 3064 with cu radiation (4o kv, 4omA). Scanning electron microscopy (SEM) using Em - 3200 at $25 \mathrm{KV}$. The morphologies and structres of the obtained products were observed by SEM and by transmission electron microscopy (TEM) on a zeiss-EM10C-100KV.

\section{Results}

The x-ray diffraction (XRD) patterns of $\mathrm{V}_{1-\mathrm{x}} \mathrm{Zr}_{\mathrm{x}}$ ONTs $(\mathrm{X}=$ 0.02 ) are shown in figure 1 . XRD meagurments were prformed on the prepared nanotubes to assess the overall phase structure. The pattern shows a variety of intense peaks occurring in between $10^{\circ}$ to $60^{\circ}$ 2theta. It can be seen that there are not significant differences among them and two set of diffraction patterns are observed in each of them: The peaks at $2 \theta<10^{\circ}$ indicated nanotubes formation the 001 (Figure 2) one corresponding to a well ordered layer structure and (hko) one corresponding to the two dimensional structure of the $\mathrm{V}(\mathrm{Zr})$ $\mathrm{O}_{\mathrm{x}}$ layers which from the walls of the nanotubes, which $\mathrm{Zr}{ }^{4+}$ ions enter the crystalline lattice of vanadium oxide layer in the nanotubes $[40,41]$. The dimension of the crystals unitcell are a function of the placement of the atoms in the unitcell. The highest intensity is at lowangle reflections. The relationship between the wavelength of the X-ray beam, $\lambda$, the angle of diffraction, 2 $\theta$, and the distance between each set of atomic plances of the crystal lattice, $\mathrm{d}$, is given by Bragg condition $\lambda=2 \mathrm{~d} \sin \theta$ where (n) represents the order of diffraction. From this equation, we can calculate the interplanar distances of the the crystalline material being studied [42] three intense peaks are apparent on pattern at d-values $3.19,6.53$ and $9.83 \mathrm{~nm}$.

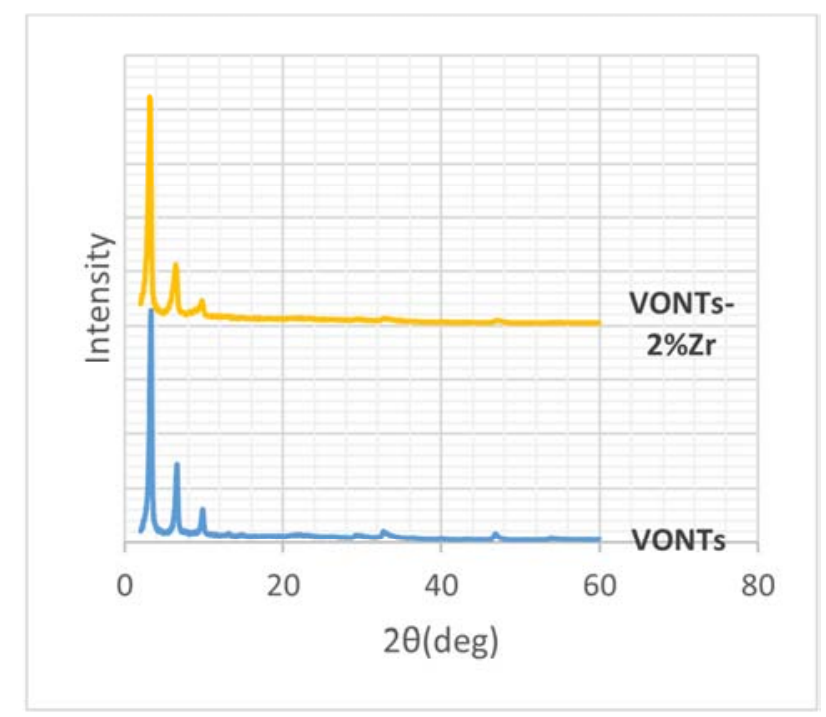

Figure 1. XRD patterns of $2 \% Z r$-doped VONTs and VONTs $\left(2 \theta=1-60^{\circ}\right)$.

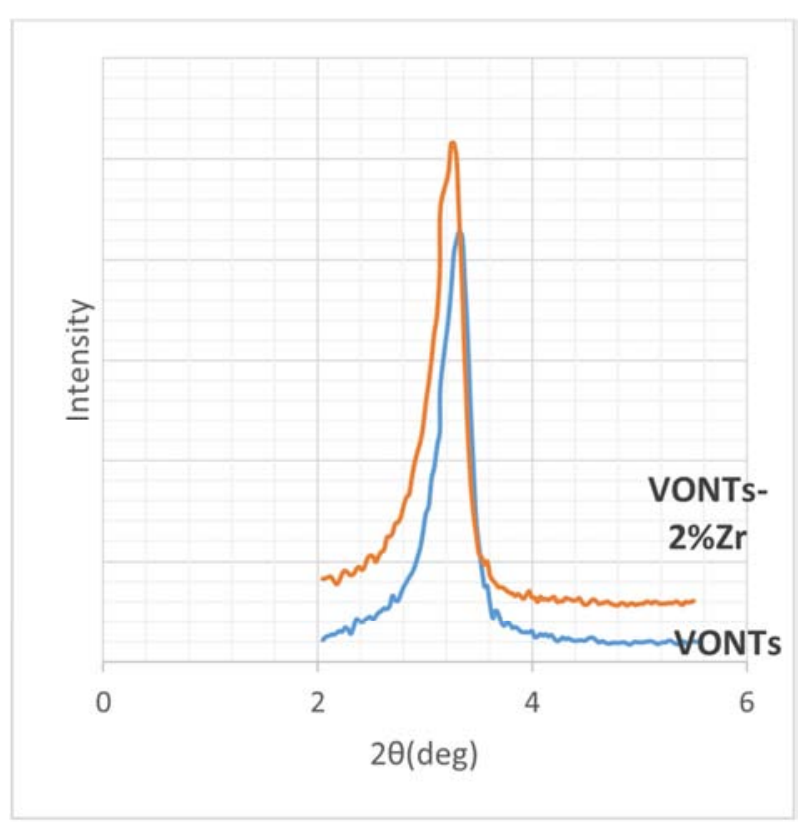

Figure 2. XRD patterns of $2 \% Z r$-doped VONTs and VONTs $\left(2 \theta=1-10^{\circ}\right)$. 
The scanning electron microscopy (SEM) shown in figure 3. The SEM image indicates that it is made almost entirely of nanotubes. As can be seen from Figure 3 the nanotubes have open ends. The SEM images indicated that the $\mathrm{V}_{0.98} \mathrm{Zr}_{0.02}$ ONTs have tubular morphology. Figure 4 shows TEM image of Zr-VONTs. The sample is multiwall nanotubes and also the average length of the $\mathrm{Zr}$-VONTs is larger than $1 \mu \mathrm{m}$.
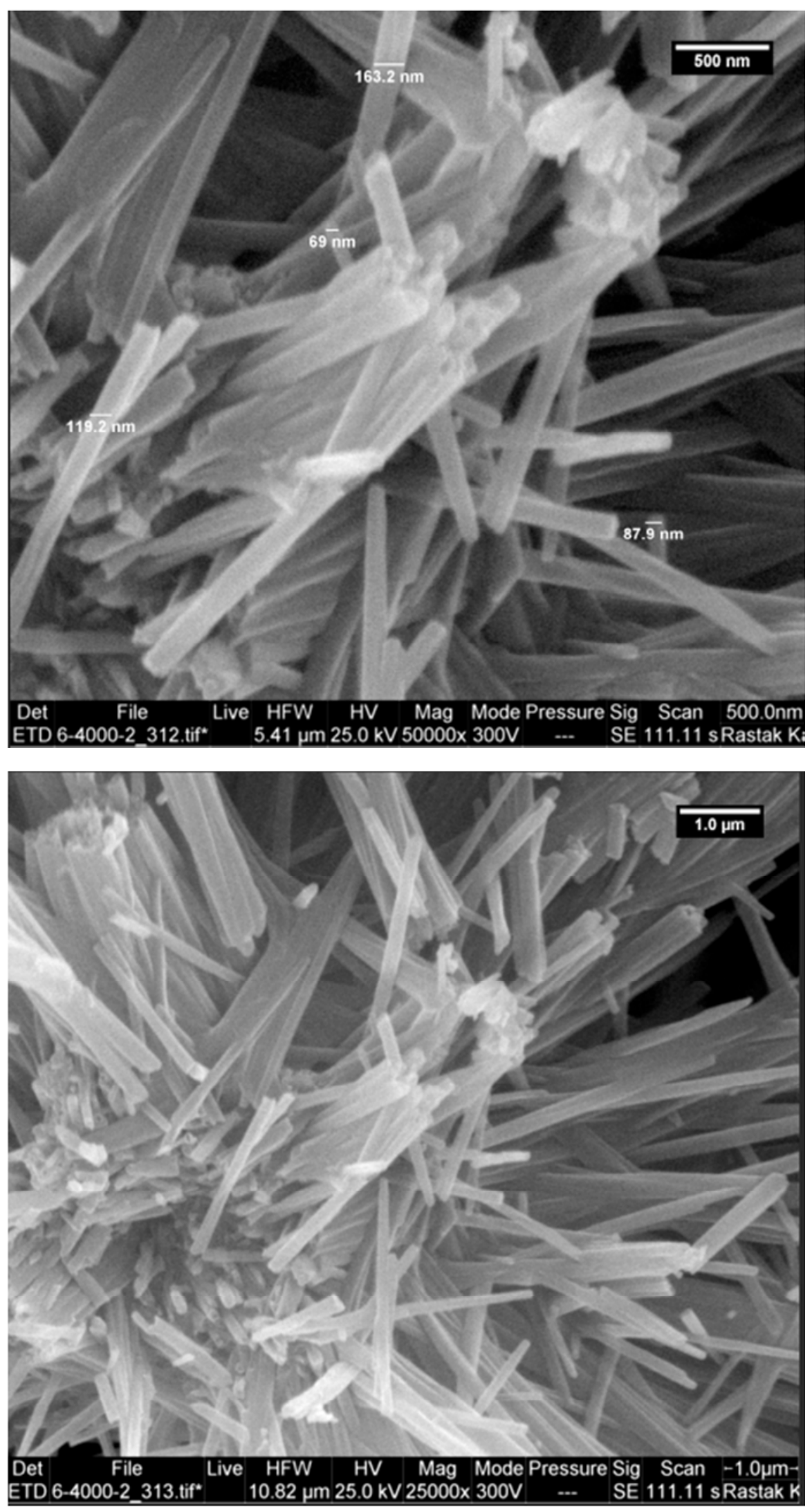


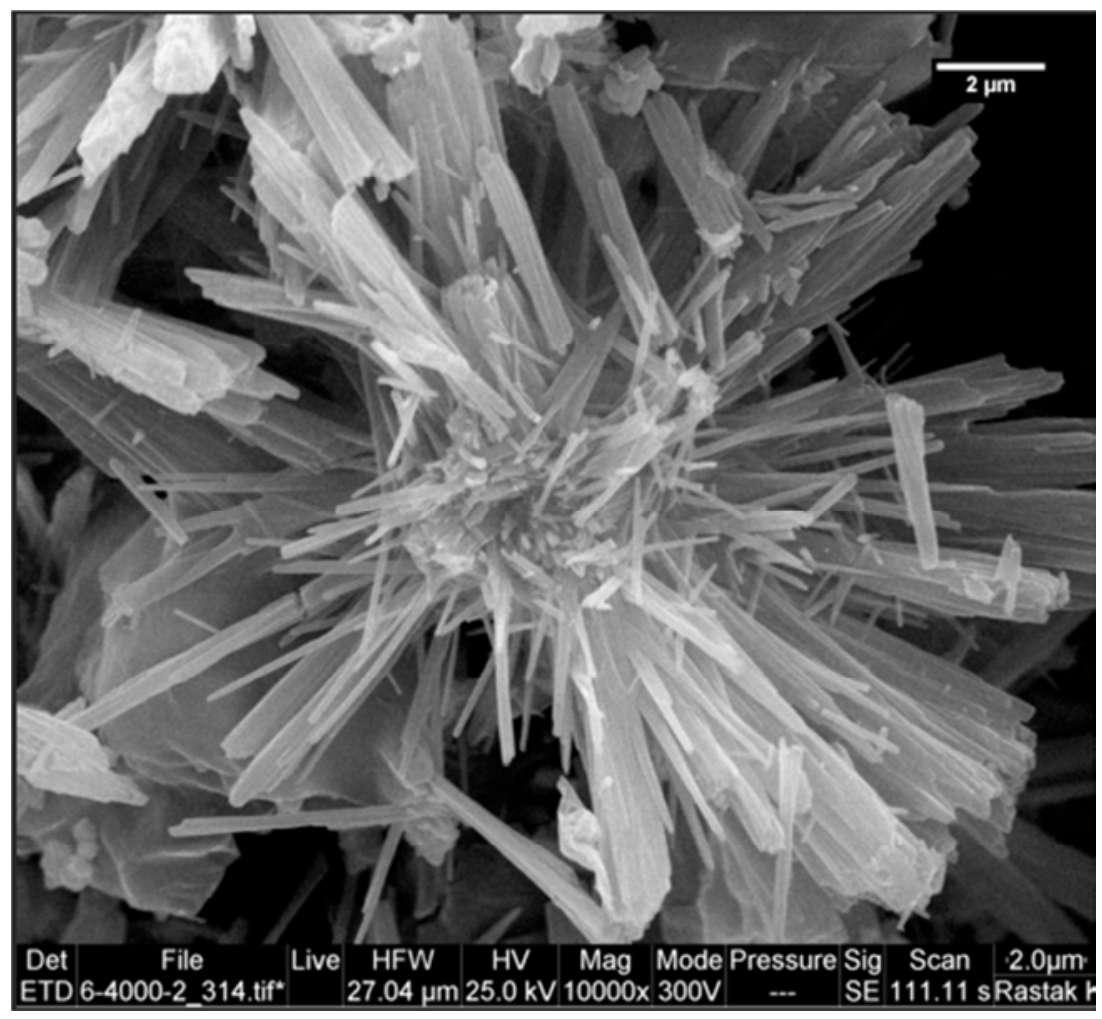

Figure 3. The SEM of VONTS-Zr.
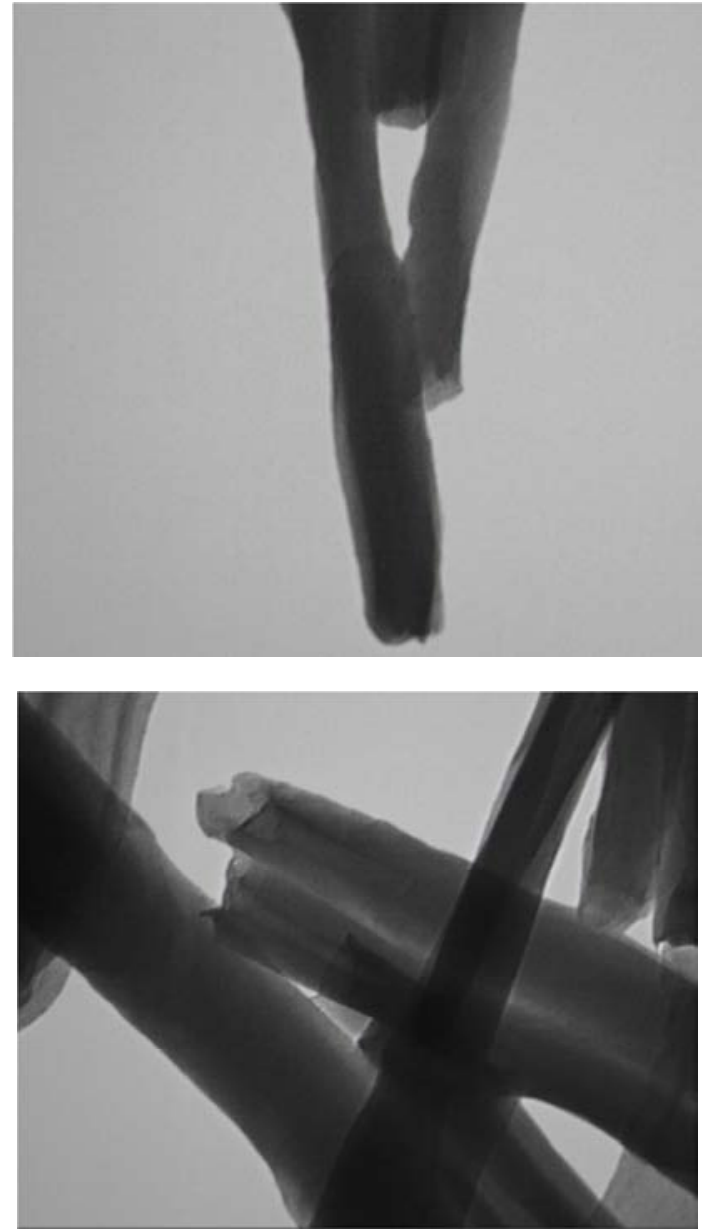

Figure 4. The TEM of VONTs-Zr.
Table 1. The d values of different samples obtained by XRD.

\begin{tabular}{lll}
\hline sample & Tempalet & $\mathbf{d}_{\mathbf{x r d}}(\mathbf{n m})$ \\
\hline $\mathrm{VONTs}$ & dodcylamin & 3.34 \\
$\mathrm{~V}_{0.98} \mathrm{Zr}_{0.02} \mathrm{ONTs}$ & dodcylamin & 3.19 \\
\hline
\end{tabular}

\section{Discussion}

The x-ray diffraction (XRD) patterns of $\mathrm{V}_{1-\mathrm{x}} \mathrm{Zr}_{\mathrm{x}}$ ONTs $(\mathrm{X}=0.02)$ are shown in figure 1 .

The peaks at $2 \theta<10^{\circ}$ indicated three intense peaks at dvalues $3.19 \mathrm{~nm}, 6.53 \mathrm{~nm}$ and $9.83 \mathrm{~nm}$. The d-value give us the interlayer distance of those nanotubes observed in the SEM and TEM results. In doped samples 001 peaks shifted toward lower diffraction angle (Figure 2) corresponding to increase of inter layer distance and that the increase of doping level of the zirconium into VONTs leads to increasing inter layer

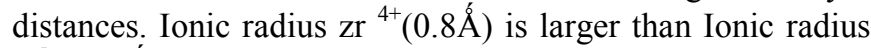
$\mathrm{V}^{5+}(0.5 \AA)$, therefore the replacement of vanadium ions with zirconium ions to be dvalue from $2.65 \mathrm{~nm}$ to $2.70 \mathrm{~nm}$.

\section{Conclusion}

The preparation of $\mathrm{V}_{0.98} \mathrm{Zr}_{0.02} \mathrm{ONT}$ s has been achieved Via hydrothermal treatment subsequently generates the tubes. The sample have a layered structures and tubular morphology. According results, doping of $0.02 \% \mathrm{wt} \mathrm{Zr}$ into VONTs prepared by hydrothermal method.

The results showed that doping of $\mathrm{V}_{0.98} Z_{0.02}$ ONTs were synthesized. In the doping done, increase of the inter layer distance $\left(\mathrm{d}_{\text {value }}\right)$ in the $\mathrm{V}_{0.98} \mathrm{Zr}_{0.02}$ ONTs with an attributed to 
the replacement $\mathrm{Zr}^{4+}$ with $\mathrm{V}^{5+}$ ions. The nanotubes have tubular morphology.

\section{References}

[1] R. Rouhani, H. R. Aghabozorg, and M. A. Asad Ababdada, synthesis and characterization of Re-, MO-, and W- doped vanadium oxide nanotubes, taylor \& francis Groups, LLC, 1018- 1021, 2011.

[2] R. Tenne, L, Margulis, M. Genut, G. modes, Nature 1992, 360, 444.

[3] Y. Feldman, E. wasserman, D. j. Srolouitz, R. Tenne, Science $1995,267,222$.

[4] N. G. chopra, R. G. Luyken, K. cherrey, V. H. Crespi, M. L. Cohen, S. G. Louie, A. Zettl, science 1995, 256, 966.

[5] H. Nakamura, Y. Matsui, L. Am. Chem, Sock. 1995, 117, 2651.

[6] P. Hoyer, Langmuir 1996, 12, 1411.

[7] M. E. Spah, P. Bitterli, R. Nesper, m. Muller, F. krumeich, H. U. Niessen, Angw Chem. Ent. Ed. 1998, 37, 1263; Angew. Chem. 1998, 110, 1339.

[8] Y. R. Hacahan, E. Grunbaum, R. Tenne, J. Sloan, J. L. Hutchison, nature 1998, 395, 337.

[9] D. H. Galvan, J. H. Kim, M. B. Maple, M. Avalos - Berja, E. Adem, Full erene Sci, Technol, 2000, 8, 143.

[10] A. L. Ivanovskii, Russ. chem. Rev. 2002, 71, 175.

[11] M. Brorson, T. W. Hansen, C. J. H. Jacobesn, J. Am. chem. Soc. $2002,124,11582$.

[12] M. E. Spahr, P. Bitterli, R. Nesper, M. Muller, F. Krumeich, H. U. Nissen, Angew. Chem., Int. Ed. 37 (1998) 1263.

[13] M. Niederberg, H. J. Muher, F. Krmeich, F. Bieri, D. Gunther, R. Nesper, Chem. Mater. 12 (2000) 1995.

[14] F. Bieri, F. Krumeich, H. J. Muher, R. Nesper, Helv. Chim. Acta 84 (2001) 3015.

[15] Grigoreva, A. V, Anikina, A. V, Tarasor, A. B, sudilin, E. A, knotko, A. V, Volkov, V. V, Dembo, K. A, Tretyakov, Y. D. micromere apology and structure of vanadium oxide nanotubes. Doklady chem, 2006, Ulo, 165-169.

[16] Li,. Zheng, L., zhang, K. F. Feng, X. Q, SU, Z. X. Ma, J. T Synthesis of Ag modified vanadium oxide nanotubes and their antibacterial properties. Mater, Res. Bull. 2008, 43, 2810 -2817.

[17] G. T. Chandrappa, No Steunous, S. Cassaignon, C. bauvais, J. Livage, Hydrothermal Synthesis of vanadium oxide nanotubes from v2 o5 gels, J of catalysis today 78 (2003) 85-89.

[18] Solsona B et al (2001) Vanadium oxide supported on mesoporous MCM-41 as selsctive catalysts in the oxidative dehydrogenation of alkanes. J Catal 203 (2):443-452.

[19] Muhr HJ, Krumeich FSchonholzer UP, Bieri F, Niederberger M, Gaukler LJ, Nesper R (2000) Adv Mater12:231.

[20] Zhang KF, Guo DJ, Liu X, Li, J, Li HL, Su ZX (2006) J Power sources 162: 1077.

[21] Spahr ME, Stoschitzki-Bitterli P, Nesper R, Haas O, Novak P
(1999) JElectrochem Soc146:278064-767.

[22] Krumeich F, Muhr HJ, Niederberger M, Bieri F, Schnyder B Nesper R (1999) J Am chem Soc 121:8324.

[23] Ledoux MJ et al (2001) High - yield butane to maleic anhydride direct oxidation on vanadyl pyrophosphate supported on heat conductive materials: $\beta-\mathrm{Sic}, \mathrm{Si}_{3} \mathrm{~N}_{4}$, and $\mathrm{BN}$, J Catal 203 (2): 495-508.

[24] Minglan Yu, Xueqin Liu, QingSu, Gas sensing of vanadium oxide nanotubes (2012), J of applied surface science 9554-9558.

[25] J. Liu, X. Wang, Q, Peng, Y. Li, Sensors and Actuators B: Chemical 115 (2006) 481-487.

[26] J. Liu, X. Wang, Q. Peng. Y Liu, Advanced Materials 17 (2005) 765-767.

[27] C. Leroy, M. Achard, O. Babot, N. Steunou, P. Masse, J. Livage, L. Binet. N. B run, R. Backov, chemistry of Materials 19 (2007) 3988-3999.

[28] Y. Li, Z. Hung, S. Rong, Sens, Mater 18 (2008) 241-249.

[29] A. Gigorieva, A. Tarasv, E, Godillin, S. Badalyan, M. Rumyantseva, A. Gaskov, A. Bikner, Y. Tretyakov, Mendeleev communications 18 (2008) 6-7.

[30] M. Kanttcheva, Physical Chemistry Chemical Physics 2 (2000) 3-43-3048.

[31] Qing Su, Xueqin Liu, Applied Surface Scince, 258 (2012) 9554-9558.

[32] MartinE. Saleta, Javier currale, H. E. Troiani, S. R. Guevara, R. Sanchez, M. Malta, R. Torresi, in Flounce of Nidopin on vanadium oxide hexadecyl amine multiwall nanotube, science direct (2007) 333-336.

[33] li. F, wang, $\mathrm{X}$, shao, C, Tan, R; liu, Y. W doped vanadium oxide nanotubes synthesis and characterization. Matter let, 2007, 61, 1328-1332.

[34] Mai, L. Q; chen, W; Xu, Q; peng, J. F, Zhu, Q. Y. Mo doped vanadium oxide nanotubes: microstructure and electrochemistry chem. Phys. Let 2003, 382, 307-312.

[35] Jiao, L. Yuan, H.; Wing, y.; Cao, J; Wang, y. Mg intercalation properties in Open - ended Vanadium oxide nanotubes Electro hem. Common. 2005, 7 (4), 431- 436.

[36] Li. Mai, wen chen, Q. XV, J. Feng pen. Q - yaoZhu, Mo doped vanadium oxide nanotubes: micro structure and electro chemistry, chemical physics letters 382 (2003) 307-317.

[37] Bicrif, Krumeich F, muh. HJ, Nesper R (2001) Heluchain Acta 84. 3015.

[38] L. Guo, J. zho, X. wang, x. xu, H. liu, and Y. li, structure and bioactivity of ziroconia, applied ceramic technology, 636- 641 (2009).

[39] Bouhedja L, Stenou N, Maquet J, Livage J (2001) J Solid State Chem162:315.

[40] J. cha, Y. J. Kim, T. J. Kim, chemo. mater. 13 (2001) 18.

[41] J. cho, Y. J. Kim, B. Park, J. Electro hem. Solid State 4 (2001) A159.

[42] Ehsan. kianfar. M. Baghernejad, Y. Rahimdashti, J of Biological forum7 (1):1671-1685 (2015). 